\title{
PATTERN OF HEAD INJURIES IN PATIENTS ADMITTED IN TERTIARY TRAUMA CENTRE.
}

1. MBBS, FCPS

Senior Registrar Neurosurgery

PUMHS, Nawabshah.

2. MS

Senior Registrar Neurosurgery PUMHS, Nawabshah.

3. FCPS

Assistant Professor Psychiatry PUMHS, Nawabshah.

4. FCPS

Associate Professor, Neurosurgery PUMHS, Nawabshah.

5. FCPS

Assistant Professor Neurosurgery PUMHS, Nawabshah.

6. FCPS

Professor Neurosurgery

PUMHS, Nawabshah.

Correspondence Address:

Dr. Muhammad Ali Jamali

Senior Registrar of Neurosurgery

People's University of Medical \&

Health Sciences for Woman (SBA).

majamali219@gmail.com

Article received on:

$14 / 05 / 2019$

Accepted for publication:

$31 / 08 / 2019$
Muhammad Ali ${ }^{1}$, Muzamil Dilber ${ }^{2}$, Moti Ram Bhatia ${ }^{3}$, Abdul Razaque Mari ${ }^{4}$, Hamid Akbar Shaikh ${ }^{5}$, Shams Raza Brohi ${ }^{6}$

ABSTRACT... Objectives: The aim of study to know the pattern of injury in terms of severity \& outcome in patients with head injuries admitted in trauma unit of a tertiary care Centre. Study Design: Descriptive Study. Setting: Trauma Centre, Peoples medical university hospital Nawabshah. Period: June, 2018 to May, 2019. Material \& Methods: This included 385 patients admitted in trauma unit of Neurosurgery Department of Peoples medical university hospital Nawabshah, through emergency Department with head injury sustained due to road traffic accident, fall, sports related injuries or Assault etc as evident on CT scan brain (plain) with bone window. Patients with poly trauma, bleeding disorders, previously operated and those who failed to turn up in OPD for follow up were excluded. Glasgow Coma Scale (GCS) was used for categorizing the subjects with head injury into mild (GCS 14-15), moderate (GCS 9-13) and severe injury (GCS 3-8). CT scan brain with bone window was done in all patients. These were then managed accordingly according to the severity of the injuries. Follow up Glasgow Coma Outcome scale was used to assess the outcome in these patients. Results: Regarding nature of traumatic injuries in these patients commonest were contusion (21.8\%), extradural hematoma (27.5\%), subdural hematoma (22.3\%), diffuse axonal injury (13.2\%), and subarachnoid hemorrhage (4.2\%). This was followed by skull fracture $(7.3 \%)$ and intracerebral hemorrhage (3.6\%). Majority of the patients were with severe head injury. Glasgow Outcome Scale of Patients at Follow- up reveled complete recovery in 106 (27.5\%), Mild disability in $81(21.0 \%)$, Moderate Disability in 64 (16.6\%), Severe Disability in $72(18.7 \%)$, Persistent Vegetative state in 36 (9.4\%), and death in 26 (6.8\%). Conclusion: Good outcome is observed in patients who are properly treated by continuous monitoring \& timely surgical intervention in a tertiary care hospital.

Key words: Head Injury, Patterns Surgical Outcome.

Article Citation: Ali M, Dilber M, Bhatia MR, Mari AR, Shaikh HA, Brohi SR. Pattern of head injuries in patients admitted in tertiary trauma Centre. Professional Med $\mathrm{J}$ 2020; 27(5):921-928. DOI: 10.29309/TPMJ/2020.27.05.3716

\section{INTRODUCTION}

Any change in mental or physical performance associated with a blow on the head, associated with or without altered level of consciousness is defined as head injury ${ }^{1}$, may be mild to severe depending on the impact \& duration of injury. In the developing and developed nations the commonest reason of mortality and morbidity are injuries related to RTA (Road traffic accidents) and this may also consequence in short term or long term disability. ${ }^{2}$ Therefore may act as a socioeconomic burden on such countries. Globally, injuries related to RTA are the most important reasons for disability adjusted life years lost and ranked at ninth level, and this is predicted to rank to third by $2020 .^{3}$ The burden of head injuries is more in Pakistan in comparison to developed nations and this increased burden is related with increased urbanization and greater motorization in our country. In Pakistan mortality rate is $15 \%$ in subjects with head injury and the annual calculated rate is estimated to be $81 / 100,000 .^{5}$ For the assessment of severity of head injury in patients GCS is used. GCS also presents a reproducible, objective assessment of neurological rating in a comparatively simple way to observe a subjects neurological state eventually. Traditionally, a GCS score of 13-15 signifies a mild injury, 9-12 signifies moderate injury, and GCS of 8 or less signifies severe injury. ${ }^{6}$ Minor injury to head represents the most common form of head injury, and is usually without neurological deficit 
and conscious level may or may not be impaired. About $75 \%$ of brain injuries are mild to moderate in nature ${ }^{7}$, subjects with head injury may have variable presentations such as from normal to confusion and deep coma, along with abnormal pupillary reactivity, CSF leak, cranial nerve VI \& VII palsies, fits and anosmia.

Thus traumatic brain injuries can have physical and behavioral impact. Social crisis, joblessness and/or disability may be the consequence such traumatic brain injuries. The aim of current research was to outline the patterns of head injury in subjects admitted in the last 2 years in emergency ward at peoples medical college hospital Nawabshah. The outcomes of current research will help in improvement of handling the subjects with head injury in form of defining management protocols for such patients. The current statistics are necessary to notify the policy makers for about the rising burden of head injury and grant a physically powerful encouragement means, preventive occasions, prerequisite for unmet capability requirements, and enhanced provision from restricted health care assets.

\section{MATERIAL \& METHODS}

This study included 385 patients admitted through Accident \& Emergency unit of neurosurgery, Nawabshah. Thereafter a complete history of all patients of head injury sustained due to RTA or fall was taken after taking written \& informed consent. Those with poly trauma and others not attending the OPD for check-ups timely were eliminated from study. After admission in head injury unit, physical examination was performed in all subjects. In needy subjects resuscitation measures were done before referring the subjects for CT scan brain. Patients were divided into severe (GCS 3-8), moderate (GCS 9-13) and mild head injury (GCS 14-15) based on GCS level. CT scan brain with bone window was done for all patients to confirm their diagnosis. Glasgow
Coma Scale (GCS) was used for categorizing the subjects with head injury into mild (GCS 14-15), moderate (GCS 9-13) and severe injury (GCS 3-8). All subjects went for CT scan brain with bone window for confirmation of diagnosis.

The outcomes at follow up of patients after traumatic head injury were observed through Glasgow outcome scale. The outcomes observed were categorized as; 1. Death, 2. Persistant vegetative state (minimum responsiveness), 3. Severe disability (subject is conscious, disabled and dependent), 4. Moderate disability: subject is disabled but independent (can work in sheltered settings) and 5. Good recovery: minor deficits with resumption of normal life.

A printed proforma was used to collect the data and this included the biodata of subjects as name, age gender, manner of trauma, neurolgical condition at arrival, type and outcome of treatment. The subjects and/or their relatives were explained about disease prognosis and the requirement of any type of medical or surgical treatment during the course of management. For the avoidance of bias or confusing issues, exclusion criterions were followed strictly.

Regarding statistical Analysis; data was entered and analyzed in statistical software (SPSS-20). Frequency and percentages were computed for categorical variables like age groups, gender, diagnosis, GCS, and surgical outcome including Glasgow outcome scale. Mean and standard deviation confidence interval were computed for quantitative measurement like age.

\section{RESULTS}

A total of 385 patients having history of head injury due to different reasons were included here.

Mean age of patients were 32.7221 with $\mathrm{SD}+15.11822$. Minimum age was 04 years and maximum was 72 years. Table-I

\begin{tabular}{|l|c|c|c|c|c|c|c|c|}
\hline & N & Range & Minimum & Maximum & \multicolumn{2}{|c|}{ Mean } & Std. Deviation \\
\hline & Statistic & Statistic & Statistic & Statistic & Statistic & Std. Error & Statistic \\
\hline Age in years & 385 & 68.00 & 4.00 & 72.00 & 32.7221 & .77050 & 15.11822 \\
\hline
\end{tabular}


Shows that there were $<10$ years of age were $28(7.3 \%)$, $10-20$ years were $57(14.8 \%)$, 21 30 years were $120(31.2 \%), 31-40$ years were $75(19.5 \%), 41-50$ years $49(12.7 \%), 51-60$ years $28(7.3 \%)$ and $>60$ years were $28(7.3 \%)$. Figure-1.

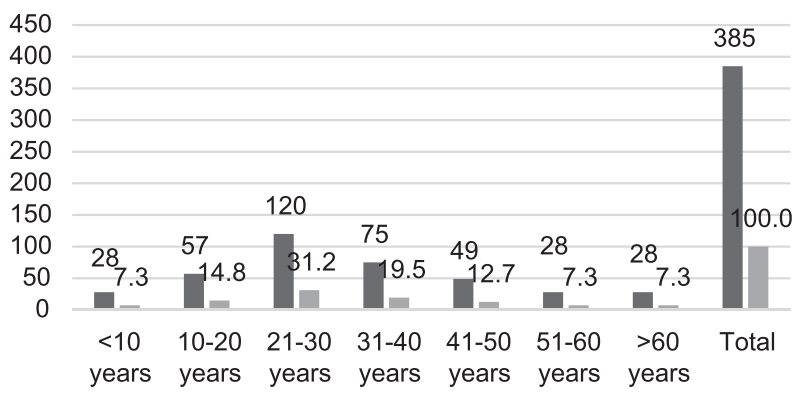

Frequency Percent

Figure-1. Age Groups

Total male were $303(78.7 \%)$ and female were $82(21.3 \%)$. Address of patients was 264(68.6\%) rural while $121(31.4 \%)$ were from urban areas. $253(65.7 \%)$ were educated at some levels, while 132(34.3\%) were uneducated. Regarding economical class, lower, middle and upper were $352(91.4 \%), 22(5.7 \%)$ and $11(2.9 \%)$ respectively. Figure-2

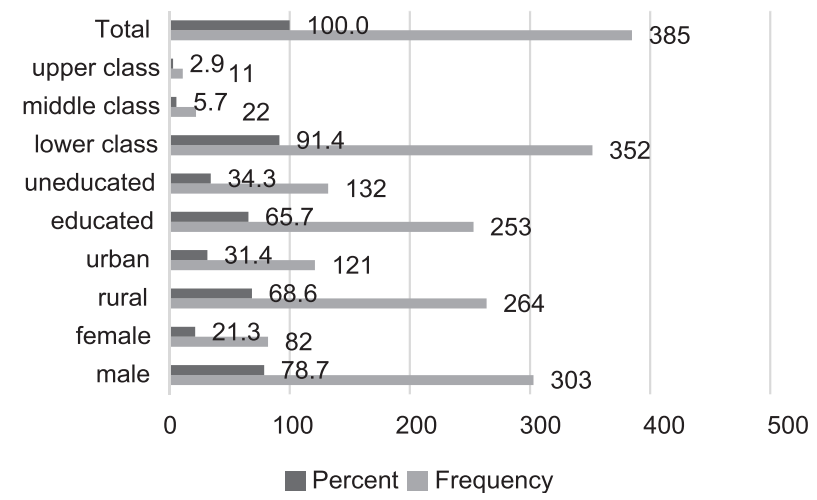

Figure-2. Demographic variables

Regarding nature of traumatic injuries in these patients commonest were contusion (21.8\%), extradural hematoma (27.5\%), subdural hematoma (22.3\%), diffuse axonal injury (13.2\%), and subarachnoid hemorrhage (4.2\%). This was followed by skull fracture $(7.3 \%)$ and intracerebral hemorrhage (3.6\%). Figure-3

Majority of patients were with severe $147(38.2 \%)$ head injury. Moderate injury was present in $120(31.2 \%)$ and mild injury $118(30.6 \%)$. Out of
385 patients admitted 267 were operated for major and minor operations, 13 Patients were reoperated due to re-bleed or incomplete evacuation of hematoma in such patients. Mortality was observed in 26(6.8\%) patients. Figure-4

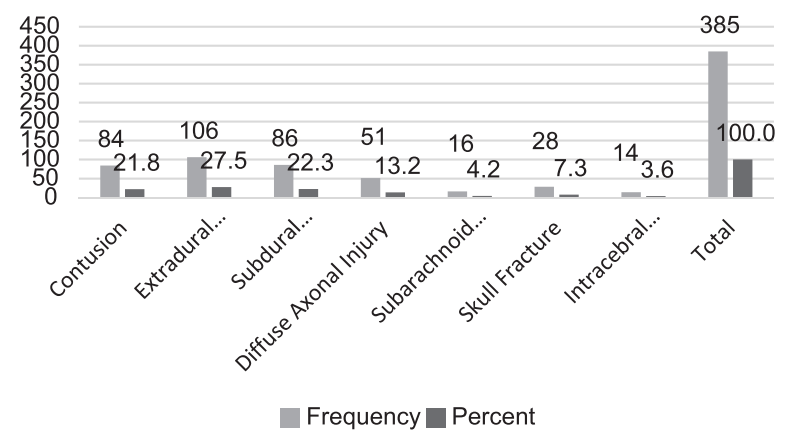

Figure 3. Nature of Lesion

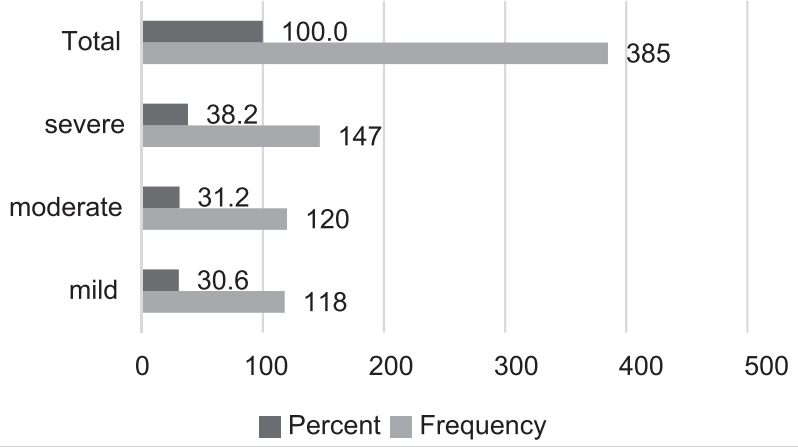

Figure-4. Severity of Injury

Majority of the patients were with severe head injury (Table-I).Glasgow Outcome Scale of Patients at Follow- up reveled complete recovery in 106 $(27.5 \%)$, Mild disability in $81(21.0 \%)$, Moderate Disability in 64 (16.6\%), Severe Disability In 72 (18.7\%), Persistent Vegetative state in 36 (9.4\%), and death in 26 (6.8\%\%). Figure-5

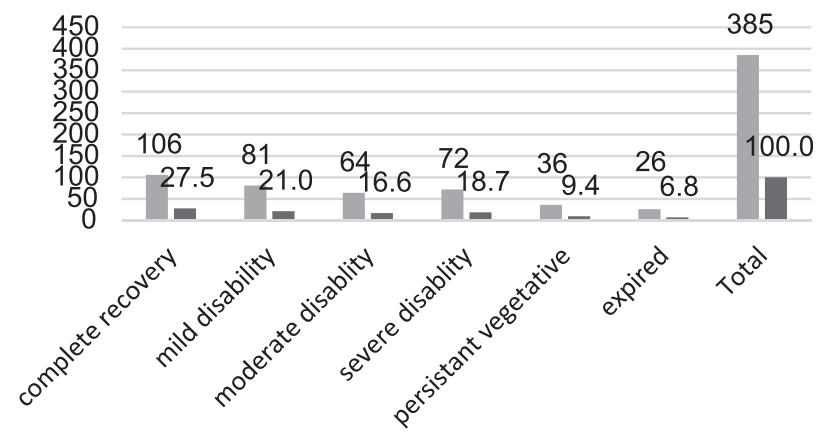

Frequency $\square$ Percent

Figure-5. Outcome of head injury 
Nature of lesion nature of injury cross tabulation

Regarding the cross tabulation of regarding nature of lesion and severity of injury contusions were present in $84(21.8 \%)$ of patients the injuries were mild, moderate and severe 12(3.1\%), 15(3.9\%) and 57(14.8\%) respectively. Regarding nature of lesion and severity of injury extradural hematoma were present in $106(27.5 \%)$ of patients the injuries were mild, moderate and severe $28(7.3 \%), 9.1(3.9 \%)$ and $43(11.2 \%)$ respectively. Regarding nature of lesion and severity of injury subdural hematoma were present in in $86(22.3 \%)$ of patients the injuries were mild, moderate and severe $23(6.0 \%), 41(10.6 \%)$ and $22(5.7 \%)$ respectively. Regarding nature of lesion and severity of injury diffuse axonal injury were present in $51(13.2 \%)$ of patients the injuries were mild, moderate and severe 11(2.9\%), 20(5.2\%) and $20(5.2 \%)$ respectively. Regarding nature of lesion and severity of injury subarachnoid hemorrhage were present $16(4.2 \%)$ of patients the injuries were mild, moderate and severe $15(3.9 \%), 0(0.0 \%)$ and $1(0.3 \%)$ respectively. Regarding nature of lesion and severity of injury skull fracture were present in $28(7.3 \%)$ of patients the injuries were mild, moderate and severe 22(5.7\%), 05(1.3\%) and $01(0.3 \%)$ respectively. Regarding nature of lesion and severity of injury intracerebral hemorrhage were present in $14(3.6 \%)$ of patients the injuries were mild, moderate and severe $07(1.8 \%)$, 04(1.0\%) and 03(0.8\%) respectively.

Chi square test for patients who were admitted Pearson chi square was 110.521, df 12, Asymp. sig. (2-sided) .000. Likelyhood ratio 108.649, df 12, Asymp. sig. (2-sided).000. Linear by linear association was 56.471, df 1, Asymp. sig. (2-sided) .000. Interval by interval pearsons $R$ value was -.383, Approx. Sig .000. Ordinal by ordinal Spearman correlation value was -.373, Approx. Sig .000. Table-II.

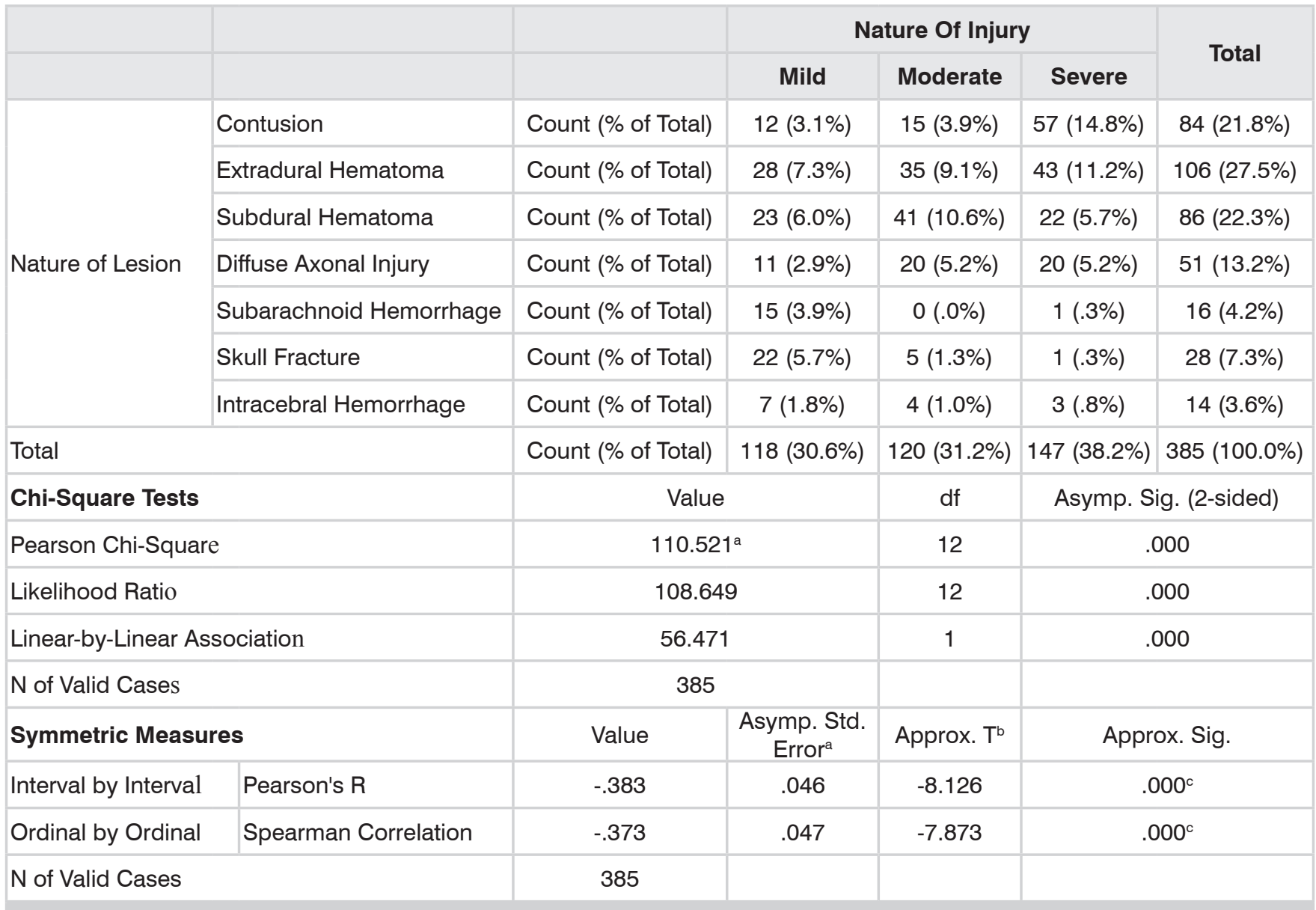

Table-II. Nature of Lesion Nature Of Injury Cross Tabulation. 


\section{Nature of Lesion and outcome Cross Tabulation.}

Regarding nature of traumatic injuries in these patients commonest were contusion total $84(21.8 \%)$, with complete recovery, mild disability, moderate disability, severe disability, persistent vegetative and expired were $31(8.1 \%)$, $22(5.7 \%), \quad 10(2.6 \%), 17(4.4 \%), 04(1.0 \%)$ and $0(0.0 \%)$ respectively. Regarding nature of traumatic injuries in these patients commonest were extradural hematoma total 106(27.5\%), with complete recovery, mild disability, moderate disability, severe disability, persistent vegetative and expired were $28(7.3 \%), 17(4.4 \%), 19(4.9 \%)$, $22(5.7 \%), 15(3.9 \%)$ and $05(1.3 \%)$ respectively. Regarding nature of traumatic injuries in these patients commonest were subdural hematoma total $86(22.3 \%)$, with complete recovery, mild disability, moderate disability, severe disability, persistent vegetative and expired were $29(7.5 \%)$, 19(4.9\%), 20(5.2\%), 04(1.0\%), 02(0.5\%) and $12(3.1 \%)$ respectively. Regarding nature of traumatic injuries in these patients commonest were diffuse axonal injury total 51(13.2\%), with complete recovery, mild disability, moderate disability, severe disability, persistent vegetative and expired were 04(1.0\%), 17(4.4\%), 11(2.9\%), $4(1.0 \%), 12(3.1 \%)$ and $03(0.8 \%)$ respectively. Regarding nature of traumatic injuries in these patients commonest were subarachnoid hemorrhage total $16(4.2 \%)$, with complete recovery, mild disability, moderate disability, severe disability, persistent vegetative and expired were $3(0.8 \%), 0(0.0 \%), 0(0.0 \%), 9(2.3 \%)$, $01(0.3 \%)$ and $03(0.8 \%)$ respectively. Regarding nature of traumatic injuries in these patients commonest were skull fracture total $28(7.3 \%)$, with complete recovery, mild disability, moderate disability, severe disability, persistent vegetative and expired were $8(2.1 \%), 3(0.8 \%), 1(0.3 \%)$, $12(3.1 \%), 02(0.5 \%)$ and $2(0.5 \%)$ respectively. Regarding nature of traumatic injuries in these patients commonest were intracerebral hemorrhage total $14(3.6 \%)$, with complete recovery, mild disability, moderate disability, severe disability, persistent vegetative and expired were $3(0.8 \%), 3(0.8 \%), 3(0.8 \%), 4(1.0 \%)$, $0(0.0 \%)$ and $1(0.3 \%)$ respectively.
Chi square test for patients who were admitted Pearson chi square was $104.748^{a}$, df 30 , Asymp. sig. (2-sided) .000. Likelyhood ratio 115.603, df 30, Asymp. sig. (2-sided).000. Linear by linear association was 9.618, df 1, Asymp. sig. (2-sided) .002. Interval by interval pearsons $\mathrm{R}$ value was .158, Approx. Sig .002. Ordinal by ordinal Spearman correlation value was .167, Approx. Sig .001.Table-III.

\section{DISCUSSION}

Contemporary trauma care is rising in its intricacy and management, even though measures taken for the reduction in the frequency of trauma universally, it seems to be the "unsolved epidemic" of the future. ${ }^{8}$ Thus traumatic brain injuries can cause, emotional insufficiency, physical and cognitive abnormalities that may direct to disability, joblessness, and/or social problems, are related with traumatic brain injuries. ${ }^{9}$ Most common affected age group was between 20 30 years, followed by 31 to 40 years in our study. This is in charge with numerous further researches carry out countrywide and globally. ${ }^{1,10}$ A common perceptions is that a large number of subjects injured in accidents especially motor vehicle, with $\mathrm{TBI}$ are young adult males. Although the majority of such injuries are related to motor vehicle accidents, but the type of injuries across various areas are different. It is observed that in developed nations motor vehicle owners usually present with $\mathrm{TBI}$, on the other hand in middle or low socio-economic nations subjects with TBI are usually due to the road traffic users motorcyclist, cyclist and pedestrians. This rising frequency of TBI subjects in middle or low socio-economic nations could be due to increasing motorization, insufficient traffic related knowledge and slow accomplishment of traffic safety rules. ${ }^{11}$

Majority of head injuries sustained due to fall were observed in elderly. Although mostly injuries sustained were mild \& moderate, but the proportions of moderate and severe cases increased gradually with age. ${ }^{14}$ The large number of falls mostly result due to falls that occurred at the same ground levels occurring at home. 


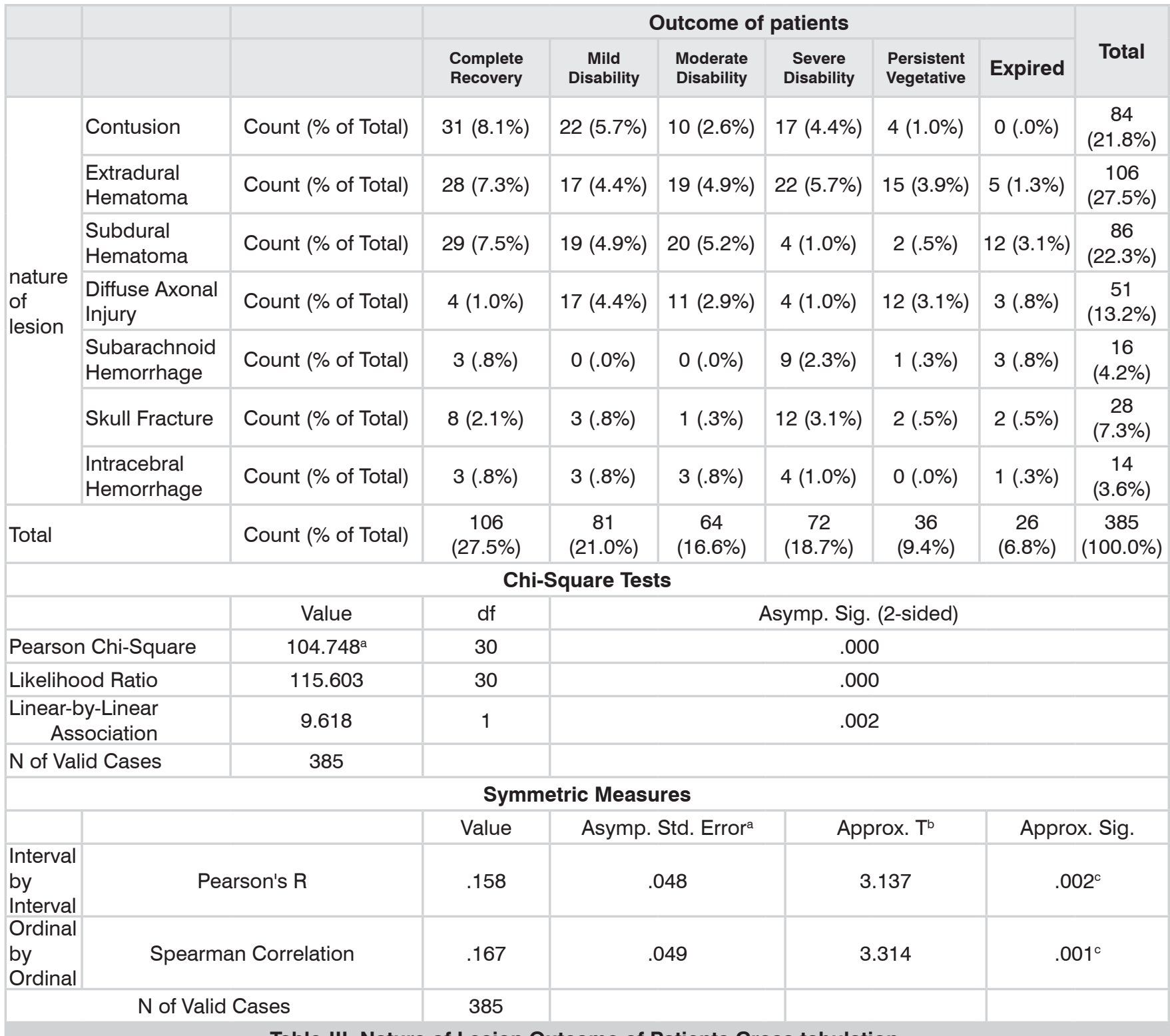

Table-III. Nature of Lesion Outcome of Patients Cross tabulation.

Subdural hematoma was the commonest finding in age group related probably to age or anticoagulants taken in this age group. The traumatic subdural haemorrhage was the most important reason of mortality in hospitalized subjects. The increasing hospitalization of subjects due to traumatic brain injury is commonly related by falls in old age, and the increase particularly in intracranial hemorrhages, these highlight the future research essential to enumerate the risks versus benefits of therapies such as anticoagulant. ${ }^{15}$ An increased mortality and unfavorable outcomes are noted in subjects with increasing old age due to severe traumatic brain injuries. ${ }^{16}$

In critical care medicine it is a main challenging issue of management in subjects with an score between 3 to 8 with severe brain injury related to trauma, and in the past two decades there is has been much improvement in managing the subjects with severe head injury. ${ }^{17}$ The acute management, throughout the "GOLDEN HOUR", i.e. duration from the time of injury to the initiation of decisive care which includes the strict ICU monitoring, should be in accordance with Head 
injury trauma ${ }^{18}$ guidelines. Majority of patients admitted in our unit were with moderate to severe head injury. There is a solid relationship between the severity of injury and the results as noted by studies. Similarly in our series high mortality and morbidity was observed in such patients who included severe disabilities and vegetative states in such patients. Therefore, extreme safety measures should be taken which also includes treatment given at site of operation along with immediate transport of such patients to trauma units in ambulances well equipped to deal with such casualties. There is higher risk of post injury longstanding impairment of everyday tasks in children who have severe brain injury due to trauma especially in early child hood. ${ }^{19}$ There is also a higher risk of longstanding impairment of routine work several years post injury especially in families who are coping poorly. ${ }^{20}$

An explanation of high mortality in our cases could be ascribed to higher age group along with majority of patients with severe head injury. Other studies $^{21,22}$ also showed high mortality rates in such patients. Mortality and severe impairment are reduced particularly with early possible diagnosis of primary brain injury and timely preventing and managing the mechanisms of secondary brain injury. Guidelines by Putapha AA et al. that were experienced on the authors' knowledge, have been directed to diagnose and treat the mild injuries, gunshot penetrating injuries of skull and brain, traumatic brain injury, rigorous outcomes of brain injury such as vegetative condition at nationwide and worldwide. ${ }^{23}$

In human culture the use of helmets are the initial methods for the self-protection. Though in the ancient times this was used principally for battle reasons, the current helmets are usually used in sports activity and transport. As the traumatic brain injury which results in increased rates of death and disability, use of helmets had remained the preventive method for traumatic head injuries since ancient times.

\section{CONCLUSION}

This study thus proved that Good outcome is observed in patients who are properly treated by continuous monitoring \& timely surgical intervention if required in a tertiary care hospital. Thus all such patients should immediately be transferred from scene of injury to units well equipped with facilities to cope with such injuries. By improving outcome in such patients with head injuries we will decrease socioeconomic burden on developing country like ours.

\section{ACKNOWLEDGMENT}

We are grateful to all the faculty and postgraduates in our scientific departments for their invaluable help in conducting this study.

\section{Conflicts of Interest}

There are no conflicts of interest.

Copyright@ 31 Aug, 2019.

\section{REFERENCES}

1. Khanzada K, Nawaz S, Siddiq M, Rehman R. Pattern of head injuries' in patients admitted in Lady Reading Hospital, Peshawar. KJMS 2011; 3: 79- 82.

2. Bener A, Rahman YS, Mitra B. Incidence and severity of head and neck injuries in victims of road traffic crashes: In an economically developed country. Int Emerg Nurs 2009; 17: 52- 9.

3. Tiruneh BT, Dachew BA, Bifftu BB. Incidence of road traffic injury and associated factors among patients visiting the emergency department of Tikur Anbessa Specialized Teaching Hospital, Addis Ababa, Ethiopia. Emerg Med Int 2014; 2014: 439818.

4. Jooma R, Ahmad S, Zarden AM. Comparison of two surveys of head injured patients presenting during a calendar year to an urban medical Centre 32 years apart. J Pak Med Assoc 2005; 55: 530-2.

5. Siddiqui A A, Zafar H, Bashir HS. An audit of head trauma care and mortality. J Coll Physicians Surg Pak $2004 ; 14: 173-7$.

6. Afzal T, Akram F, Durrani M. Role of computed tomography in predicting clinical outcome in patients with minor head injury. J Ayub Med Coll Abbottabad 2013; 25: 187- 90.

7. Bajwa NM, Halavi S, Hamer M, Semple BD, NobleHaeusslein LJ, Baghchechi M, et al. Mild Concussion, but Not Moderate Traumatic Brain Injury, Is Associated with Long-Term Depression-Like Phenotype in Mice. PLoS ONE 2016; 11: e0146886. 
8. Naveed D, Bhatti SN, Akbar M, Aurangzeb A. Etiology, Presentation and outcome of head injury patients admitted in Ayub Teaching Hospital, Abbottabad. KMJ 2010; 2:45 -8.

9. Baratz R, Tweedie D, Rubovitch V, Luo W, Yoon JS, Hoffer BJ. Tumor necrosis factor-a synthesis inhibitor, 3, 6'-dithiothalidomide, reverses behavioral impairments induced by minimal traumatic brain injury in mice. J Neurochem 2011; 118:1032-42.

10. Dubey A, Shibu V. Pillai, Sastry VR. Kolluri. Does volume of extradural hematoma influence management strategy and outcome. Neurlnd 2004; 52: 443-5. 20.

11. Roozenbeek B, Maas AIR, Menon DK. Changing patterns in the epidemiology of traumatic brain injury. Nature Reviews Neurology 2013; 9: 231-6

12. Kimbler DE, Murphy M, Dhandapani KM. Concussion and the adolescent athlete. The Journal of neuroscience nursing: journal of the American Association of Neuroscience Nurses. 2011 Dec;43(6).

13. Rosenthal JA, Foraker RE, Collins CL, Comstock RD. National high school athlete concussion rates from 2005-2006 to 2011-2012. Am J Sports Med 2014; 42: 1710-5.

14. Xing XY, Xu W, Chen YJ, Liu ZR, Jia SC, Xie JR et AL. Trend and characteristics of fall in elderly adults based on data from national injury surveillance sentinel hospitals in Anhui province, 2006-2014. Zhonghua Liu Xing Bing Xue Za Zhi 2016; 37:702-7.

15. Harvey LA, Close JC. Traumatic brain injury in older adults: Characteristics, causes and consequences. Injury 2012; 43:1821-6.

16. Røe C, Skandsen T, Manskow U, Ader T, Anke A. Mortality and one-year functional outcome in elderly and very old patients with severe traumatic brain injuries: Observed and predicted. Behav Neurol 2015; 2015:845491.
17. Haddad SM, Arabi YM. Critical care management of severe traumatic brain injury in adults. Scand $J$ Trauma Resusc Emerg Med 2012; 20: 12.

18. Mangat HS. Severe traumatic brain injury. Continuum (Minneap Minn) 2012; 18: 532-46.

19. Catroppa C, Anderson VA, Morse SA, Haritou F, Rosenfeld JV. Outcome and predictors of functional recovery 5 years following pediatric traumatic brain injury (TBI). J Pediatr Psychol 2008; 33:707-18.

20. Anderson VA, Catroppa C, Dudgeon P, Morse SA, Haritou F, Rosenfeld JV. Understanding predictors of functional recovery and outcome 30 months following early childhood head injury. Neuropsychology 2006; 20:42-57.

21. Jovanovic B, Milan Z, Djuric O, Markovic-Denic L, Karamarkovic A, Gregoric P, Doklestic K, Avramovic $\mathrm{J}$, Velickovic J, Bumbasirevic V. Twenty-eight-day mortality of blunt traumatic brain injury and coinjuries requiring mechanical ventilation. Medical principles and practice. 2016;25(5):435-41.

22. Khajavikhan J, Vasigh A, Kokhazade $\mathrm{T}$, Khani A. Association between hyperglycaemia with neurological outcomes following severe head trauma. Journal of clinical and diagnostic research: JCDR. 2016 Apr;10(4):PC11.

23. Potapov AA, Krylov VV, Gavrilov AG, Kravchuk $A D$, Likhterman LB, Petrikov SS et al. [Guidelines for the anagement of severe traumatic brain injury. Part 3. Surgical management of severe traumatic brain injury (Options)]. Zh Vopr Neirokhirlm N N Burdenko 2016; 80: 93-101.

24. Sone JY, Kondziolka D, Huang JH, Samadani U. Helmet efficacy against concussion and traumatic brain injury: a review. Journal of neurosurgery. 2017 Mar $1 ; 126(3): 768-81$.

\begin{tabular}{|c|c|c|c|}
\hline \multicolumn{4}{|c|}{ AUTHORSHIP AND CONTRIBUTION DECLARATION } \\
\hline Sr. \# & Author(s) Full Name & Contribution to the paper & Author(s) Signature \\
\hline 1 & Muhammad Ali & Basic concept + Data galleries. & \\
\hline 2 & Muzamil Dilber & Introduction. & \\
\hline 3 & Moti Ram Bhatia & Material and Methods. & \\
\hline 4 & Abdul Razaque Mari & Discussion. & \\
\hline 5 & Hamid Akbar Shaikh & Data analysis. & \\
\hline 6 & Shams Raza Brohi & over new progressives & \\
\hline
\end{tabular}

